\title{
Validation of Ethno Veterinary Medicines Used for Anoestrum Treatment in Cattle
}

\author{
K. Devaki ${ }^{*}$, P. Mathialagan ${ }^{2}$, V. E. Sabarathnam², \\ P. Kumaravel ${ }^{2}$ and S. M. K. Karthickeyan ${ }^{3}$ \\ ${ }^{1}$ Krishi Vigyan Kendra (TANUVAS), Kattupakkam, Tamil Nadu, India \\ ${ }^{2}$ Department of Veterinary and Animal Husbandry Extension, Madras Veterinary College, \\ Chennai-7, Tamil Nadu, India \\ ${ }^{3}$ Department of Animal Genetics and Breeding, Madras Veterinary College, Chennai-7, \\ Tamil Nadu, India \\ *Corresponding author
}

\section{A B S T R A C T}

Keywords

Validation, Quik method, EVM,

Indigenous

technical

knowledge

Article Info

Accepted:

18 May 2018

Available Online:

10 June 2018
Indigenous technical knowledge plays an important role in traditional dairy farming. In due course, there is danger of extinction of this knowledge. It is of paramount importance to document these practices and to assess their validity. Hence an attempt was made to document the prevailing ITK's among the 10 dairy cattle owners each from four districts viz., Tirunelveli, Namakkal, Vellore and Thiruppur districts and also comparing the present ITKs with the Modern Veterinary drugs for Anestrum. A sample of 40 farmers was interviewed through structured interview schedule to document the ITK's used for controlling Anaestrum. The five ITKs for the anaestrum condition were subjected to validation test through the QuIK (Quantification Indigenous Technical Knowledge) method. All the ITKs were found to be effective against anaestrum. However, these were perceived to be comparatively less effective than the Modern Veterinary Drug (MVD) in numbers of animals cured and quickness of healing. The Indigenous Practices were perceived better than MVD in respect of their availability, lesser side effects, and lower cost.

\section{Introduction}

The World Health Organization (WHO) estimates that 80 to 90 per cent of the world's population still rely on traditional medicine and traditional healers for their health care needs. In another report, World Health Organization (WHO) recorded more than 80 per cent of Asia's population and over 50 per cent of the population in India cannot afford 
formal health care systems and are dependent on culturally familiar, technically simple, financially affordable and effective traditional medicines (Duke, 2017). The figures are the same and will remain the same for livestock because their owners continue to do what they can to protect the health of their animals. There is also a dramatic increase in traditional medicine system in case of companion animal health care in USA and Europe. Herbal medicinal products represent a fast growth area of health-care products for companion animals.

Traditional practices can be used to provide economical solutions to improve productivity of animals and reduction in poverty of the poor farmers (Dilshad et al., 2008). In India, this aspect has received very little attention in modern research and less efforts have been made to upgrade the traditional practices and information available with the local healers/farmers that have trickled down from their fore-fathers. Some work on documentation of ethno-veterinary practices and validation of indigenous medicinal plants exists in the form of published literature but as compared to the huge knowledge in the country, very little information have so far been collected.

Any practice, considered valid and fruitful, will have a scientific basis for its successful results. Farmers are not able to explain the scientific rationale behind indigenous practices; therefore, scientists are responsible for testing and verifying those practices and finding out their rationality.

Thus, one simple method of validation of IK has been studying the rationality of the given IK by scientists. Only a few EVM's were validated in veterinary practice. Hence a study was conducted to validate ethno veterinary medicines used for anoestrum treatment in cattle.

\section{Materials and Methods}

Validation of EVMs had been done through QuIK (Quantification of Indigenous Knowledge) method by some identified persons who were experienced in particular ITK(s), using the method (QuIK) developed by De Villiers in 1996. The basic premise of this method is that farmers know and understand the environment in which they farm and that answers to many questions can be found in the collective experience of the farming community and doing informal experiments over years. It can be used to unpack the practices of successful farmers, so that information can be disseminated to a wider group of farmers. QuIK methodology represents a rapid and relatively cheap way to elicit indigenous technical knowledge.

Farmers who were experienced in the particular EVM taken for validation were chosen. In QuIK, matrix ranking is combined with an interview schedule to elicit numerical data from experienced farmers. The matrix was designed through preliminary discussions with farmers and was then obtained as part of a systematic process to obtain quantitative data. The experienced respondents were asked to weigh the $\operatorname{EVM}(\mathrm{s})$ in comparison with modern veterinary drugs for its performance on different criteria and effectiveness (No. of animals cured, cost effectiveness, quickness in healing, ease in preparation, side effects and availability).

The respondents were asked to put required numbers of pieces of stone out of 10 in each block of matrix. Unlike others, in case of side effects, the greater value of stones indicates fewer side effects. The same matrix was used to interview a number of farmers and the data from each farmer were treated as an independent result. Then the data were put in the statistical analysis (a standard analysis of Variance, ANOVA). 
Data collected from the respondents on several criteria were subjected to one-way analysis of variance (Snedecor and Williams 1989).

Analysis was carried out separately for each group of data under each criterion under a particular disease studied. To test the difference of means among alternatives, Duncan's Multiple Range Test as modified by Kramer (1957) was followed.

The linear model chosen for ANOVA was,

$Y i j=\mu+t i+e i j$

Where,

Yij $=$ Observation of $\mathrm{jth}$ respondent to ith alternative

$\mu=$ Overall mean

$\mathrm{ti}=$ Effect of $i$ th alternative

eij = Residual, distributed with mean "0" and variance "1"

\section{Results and Discussion}

A total of five EVMs, commonly used for treatment of anoestrum in cattle were selected based on their degree of use throughout the region under study. The scores given by the key informants were tabulated and subjected to one way of analysis (ANOVA) for finding out variability between different alternatives (EVM1, EVM2, EVM3, EVM4, EVM5 and MVD1). For significant alternatives, Duncan's Multiple Range test (DMRT) was done to test the significant difference of means between different attributes of each group and to identify the best practice among them.

The validation on different alternatives used for anaoestrum treatment was carried out based on following alternatives:
EVM1: Half of a coconut and10 gms of rhizome of Turmeric (Curcuma longa) are to be grounded and administered orally for 10 days

EVM2: 150 gms of Winter cherry [Ashwagandha (Withania Somifera)], $150 \mathrm{gms}$ of Gingely seeds mixed and grounded and mixed with poultry eggs ( 2 numbers) and 2 fruits of Bananas (finger banana) were mixed and administered for 7 days.

EVM3: Feeding curry leaves (Murraya Koenigii) for 10 days

EVM4: Twelve pieces of Banana (Musa Paradisica) mixed with 400 gms of sugar and administered for 2 days

EVM5: 100 gms of Ashoka tree (Saraca asoca) bark was grounded and administered to cattle for a week.

The effectiveness of the ITK was measured in terms of the number of animals cured by it (Table 1) showed that all the alternatives differed significantly $(\mathrm{p}<0.005)$ with each other regarding effectiveness in curing anoestrum.

The EVM3 was most effective (6.98) in this regard among all the alternatives, whereas, MVD1 was more effective as compared to EVM4 and EVM1.

Use of all EVMs was highly cost effective over MVD. It might be due to the fact that the local farmers had to buy the MVD from the market, whereas, curry leaves was available in the study area. As far as quickness in healing was concerned, EVM3 and MVD1 rendered the curing process most quickly, followed by EVM2, EVM4 and EVM1. As such, between the five EVMs studied for anaoestrum, feeding curry leaves was more effective in curing anaoestrum. 
Table.1 Duncan's Multiple Range to find difference of means among different alternatives for Anoestrum in cattle (EVM1): Feeding of coconut \& turmeric; EVM2: Feeding of Winter Cherry

(Ashwagandha), Gingely seeds, Poultry eggs, and Bananas; EVM3: Feeding of curry leaves;

EVM4: Feeding banana and sugar; EVM5: Feeding Ashoka tree bark; MVD1- Modern Veterinary Drug) $(\mathrm{N}=40)$

\begin{tabular}{|c|l|c|c|c|c|c|c|c|c|}
$\begin{array}{c}\text { S. } \\
\text { No. }\end{array}$ & \multicolumn{1}{|c|}{ Parameters } & \multicolumn{9}{|c|}{ Practices } & F value & P value \\
\cline { 2 - 10 } & & EVM1 & EVM2 & EVM3 & EVM4 & EVM5 & MVD1 & & \\
\hline $\mathbf{1}$ & Effectiveness & $5.08^{\mathrm{b}}$ & $5.45^{\mathrm{b}}$ & $6.98^{\mathrm{c}}$ & $5.45^{\mathrm{b}}$ & $3.30^{\mathrm{a}}$ & $6.88^{\mathrm{c}}$ & 29.320 & $<0.001^{* *}$ \\
& & $(1.76)$ & $(1.77)$ & $(1.48)$ & $(1.77)$ & $(1.26)$ & $(1.32)$ & & \\
\hline $\mathbf{2}$ & \multirow{2}{*}{ Low cost/ no cost } & $3.90^{\mathrm{b}}$ & $4.43^{\mathrm{b}}$ & $8.18^{\mathrm{d}}$ & $4.43^{\mathrm{b}}$ & $5.63^{\mathrm{c}}$ & $1.70^{\mathrm{a}}$ & 96.083 & $<0.001^{* *}$ \\
& & $(2.25)$ & $(1.38)$ & $(0.90)$ & $(1.38)$ & $(1.13)$ & $(0.65)$ & & \\
\hline $\mathbf{3}$ & User friendly & $5.43^{\mathrm{b}}$ & $7.50^{\mathrm{c}}$ & $7.60^{\mathrm{c}}$ & $7.50^{\mathrm{c}}$ & $7.35^{\mathrm{c}}$ & $3.03^{\mathrm{a}}$ & 111.387 & $<0.001^{* *}$ \\
& & $(1.80)$ & $(1.001)$ & $(0.81)$ & $(1.001)$ & $(0.62)$ & $(1.03)$ & & \\
\hline $\mathbf{4}$ & Quickness in & $3.68^{\mathrm{b}}$ & $2.28^{\mathrm{a}}$ & $4.30^{\mathrm{c}}$ & $2.28^{\mathrm{a}}$ & $4.20^{\mathrm{c}}$ & $6.95^{\mathrm{d}}$ & 108.995 & $<0.001^{* *}$ \\
& healing & $(1.25)$ & $(0.82)$ & $(1.32)$ & $(0.82)$ & $(1.16)$ & $(0.75)$ & & \\
\hline $\mathbf{5}$ & Ever ready & $3.58^{\mathrm{b}}$ & $7.63^{\mathrm{c}}$ & $7.85^{\mathrm{c}}$ & $7.53^{\mathrm{c}}$ & $2.65^{\mathrm{a}}$ & $2.63^{\mathrm{a}}$ & 377.419 & $<0.001^{* *}$ \\
& ingredients & $(1.24)$ & $(0.63)$ & $(0.83)$ & $(0.75)$ & $(0.83)$ & $(0.67)$ & & \\
\hline
\end{tabular}

Note:

1. The values within bracket refers to SD; 2 . **- It is highly significant at 1 per cent level

About user friendly, curry leaves was found in readymade form, whereas, in case of MVDs, the farmers had to purchase it from the medical shops. For this reason, EVM3 might be easier to prepare than MVD1. MVD1 was perceived to have more quickness in healing than all the EVMs used. In terms of availability, EVM3, EVM2 and EVM4 were rated better than EVM1, EVM5 and MVD1. There was no significant difference between the EVMs ( $\mathrm{p}<0.005)$. This might be due to the fact that MVD1, EVM5 and EVM1 were not easily accessible, whereas, ingredients of EVM3, EVM2 and EVM4 were locally available and easily accessible to the farmers.

The critical perusal of the data revealed that the traditional farmers, keeping the costeffectiveness, ever ready ingredients, user friendly and effectiveness in view, favourably accepted the EVM3. However, MVD recorded higher ranking in criteria like quickness in healing and effectiveness. The viable alternatives, based on the available criteria, seemed to be the EVM3 from the traditional farmer's perspective.

It has been concluded that the poor availability of economic resources in the study area have caused lesser influence of scientific dairy farming technologies in the region. As a result of which, over the years of experimentations, dairy farmers of this region have evolved an alternative knopwledge base for the treatment of their animals. The farmers of this region have location specific knowledge of traditional management of anestrum in cows. This common practice helps the farmers to increase their net income and improve socio-economic status. This validation can be utilized to formulate the hypotheses for designing and implementing research project on location specific and farmer's knowledge based participatory 
research for efficient natural resource management.

\section{Acknowledgement}

Authors are highly thankful to the farmers for sharing their valuable knowledge and expertise on indigenous traditional knowledge of anaestrum in cows.

\section{References}

De Villiers, A.K., 1996. Quantifying indigenous knowledge: a rapid method for assessing crop performance without field trials. Network Paper-Agricultural Administration (Research and Extension) Network (United Kingdom)
Dilshad, S. M. R., Iqbal, Z., Muhammad, G., Iqbal, A., \& Ahmed, N. 2008. An inventory of the ethnoveterinary practices for reproductive disorders in cattle and buffaloes, Sargodha district of Pakistan. Journal of ethnopharmacology, 117(3), 393-402.

Duke, J.A., 2017. Handbook of phytochemical constituents of GRAS herbs and other economic plants. Herbal Reference Library. Routledge.

Kramer, C. Y. 1957. Extension of multiple range tests to group correlated adjusted means. Biometrics, 13(1): 13-18.

Snedecor, G. W. C., \& William, G.1989. Statistical methods. Snedecor and William G. Cochran (No. QA276. 12. S6313 1989.).

\section{How to cite this article:}

Devaki K., P. Mathialagan, V. E. Sabarathnam, P. Kumaravel and Karthickeyan S. M. K. 2018. Validation of Ethno Veterinary Medicines Used for Anoestrum Treatment in Cattle. Int.J.Curr.Microbiol.App.Sci. 7(06): 1732-1736. doi: https://doi.org/10.20546/ijcmas.2018.706.205 